\title{
Minimum Clinically Important Difference in 30-s Sit-to-Stand Test After Pulmonary Rehabilitation in Subjects With COPD
}

\author{
Andrea Zanini, Ernesto Crisafulli, Michele D’Andria, Cristina Gregorini, Francesca Cherubino, \\ Elisabetta Zampogna, Andrea Azzola, Antonio Spanevello, Nicola Schiavone, and Alfredo Chetta
}

\begin{abstract}
BACKGROUND: The sit-to-stand (STS) test is a feasible tool for measuring peripheral muscle strength of the lower limbs. There is evidence of increasing use of STS tests in patients with COPD. We sought to evaluate in subjects with COPD the minimum clinically important difference in 30-s STS test after pulmonary rehabilitation. METHODS: Stable COPD subjects undergoing a 30-s STS test and a 6-min walk test (6MWT) before and after pulmonary rehabilitation were included. Responsiveness to pulmonary rehabilitation was determined by the change in 30-s STS test results ( $\Delta$ 30-s STS) before and after pulmonary rehabilitation. The minimum clinically important difference was evaluated using an anchor-based method. RESULTS: 96 subjects with moderate-to-severe COPD were included. At baseline, 30-s STS test results were significantly related to distance covered in a 6MWT (6MWD) $(r=0.65, P<.001)$, FVC $(r=0.46, P<.001), \mathrm{P}_{\mathrm{acO}_{2}}(r=-0.42$, $P<.001), \mathrm{FEV}_{1}(r=0.39, P<.001)$, and age $(r=-0.31, P=.002)$. After pulmonary rehabilitation, a significant improvement in 30-s STS test results was observed (mean difference +2 repetitions, $P<.001)$. The $\Delta 30$-s STS was positively related to $\triangle 6$ MWD $(r=0.62, P<.001)$, transitional dyspnea index $(r=0.67, P<.001)$, and baseline residual volume $(r=0.27, P=.007)$. The receiver operating characteristic curves method identified a $\Delta$ 30-s STS cut-off of 2 repetitions as the best discriminating value (area under the curve: $0.892, P<.001$ ) to identify the minimum clinically important difference for $\triangle 6 \mathrm{MWD}(30 \mathrm{~m})$. In a multivariate logistic regression model, baseline 30-s STS (odds ratio $2.63 ; 95 \%$ CI $1.09-6.35, P=.031$ ) and diffusing capacity of the lung for carbon monoxide ( $<53 \%$ predicted) (odds ratio $2.49,95 \%$ CI 1.04-5.98, $P=.041$ ) predict the risk to have a $\Delta$ 30-s STS $\geq 2$ repetitions. CONCLUSIONS: Our study indicates that in stable subjects with moderate-to-severe COPD, the 30-s STS test was a sensitive tool to assess the efficacy of pulmonary rehabilitation. A $\Delta$ 30-s STS of $\geq 2$ repetitions represented the minimum clinically important difference, which may be predicted by the baseline ability in the 30-s STS test and lung function in terms of diffusing lung capacity (ClinicalTrials.gov registration NCT03627624). Key words: COPD; sit-to-stand test; minimum clinically important difference; pulmonary rehabilitation; physical ability; diffusing lung capacity. [Respir Care 2019;64(10):1261-1269. () 2019 Daedalus Enterprises]
\end{abstract}

\section{Introduction}

Skeletal muscle dysfunction is a clinically relevant extrapulmonary manifestation of COPD ${ }^{1,2}$; accordingly, re-

Drs Zanini and Schiavone are affiliated with Pulmonary Rehabilitation, Clinic of Rehabilitation, Ente Ospedaliero Cantonale, Novaggio, Switzerland. Drs Crisafulli and Chetta are affiliated with the Respiratory Disease and Lung Function Unit, Department of Medicine and Surgery, University of Parma, Parma, Italy. Ms D'Andria and Ms Gregorini are affiliated with the Division of General Medicine, Ospedale Malcantonese, Castelrotto, Switzerland. Dr Cherubino and Ms Zampogna are affil- sistance training of peripheral muscles has been strongly recommended during a pulmonary rehabilitation (PR) program. ${ }^{3}$ Resistance training has a greater potential to improve muscle mass and strength than endurance training. ${ }^{4,5}$ In addition, strength training induces less dyspnea during

iated with the Division of Pulmonary Rehabilitation, Istituti Clinici Scientifici Maugeri, IRCCS, Tradate, Italy. Dr Azzola is affiliated with the Pulmonology Service, Department of Internal Medicine, Ente Ospedaliero Cantonale, Lugano, Switzerland. Dr Spanevello is affiliated with the Department of Medicine and Surgery, Respiratory Diseases, University of Insubria, Varese-Como, Italy. 
the exercise period than aerobic training, making this rehabilitative strategy suitable for patients with moderateto-severe $\mathrm{COPD}$, even during exacerbation. ${ }^{6,7}$

The sit-to-stand (STS) test is a feasible tool for measuring peripheral muscle strength of the lower limbs. The STS test has been developed for elderly people with different chronic diseases because the maneuver of standing up from a seated position is an essential activity of daily living. ${ }^{8}$ This ability to stand up from a chair is an important component of maintaining independence among the elderly because this movement depends on stability and balance. ${ }^{9}$ The STS test can be performed in any health care setting because it requires minimal equipment (eg, a conventional chair and a stopwatch), and it is easy and quick to perform for most subjects.

Variations of the STS test procedure include the maximum number of times a patient can stand up and sit down on a regular chair in a given period of time, usually $30 \mathrm{~s}$ or $1 \mathrm{~min},{ }^{10-12}$ or the time taken to perform a given number of sit-to-stand maneuvers (usually 5 repetitions). ${ }^{13}$ Moreover, to improve the interpretability and clinical usefulness of field tests such as the STS test, relevant reference values and reference equations have been established.14-17 Previous research reported that scores on the 30-s STS test and the 1-min STS test correlate well with the 6-min walk test (6MWT) and the 1-repetition maximum strength test, which are considered the accepted standard for assessing muscle strength in non-laboratory situations. ${ }^{10-13,18}$ The minimum clinically important differences for the 1-min STS test and the 5-repetition STS test after PR have been established in stable subjects with COPD. ${ }^{19-21}$ No study has specifically investigated the minimum clinically important difference of the 30-s STS test after PR. Therefore, we sought to evaluate the responsiveness of the 30-s STS test and to assess the minimum clinically important difference in a large cohort of subjects with moderateto-severe and clinically stable COPD who were undergoing a PR program.

\section{Methods}

\section{Study Design}

Stable patients with COPD who were undergoing the 30-s STS test and the 6MWT before and after PR were included. Responsiveness to PR was determined by changes

\footnotetext{
The authors have disclosed no conflicts of interest.
}

Correspondence: Andrea Zanini MD, Clinica di Riabilitazione Ente Ospedaliero Cantonale, Via Drive E Schwarz 6, 6986 Novaggio, Switzerland. E-mail: andrea.zanini2@eoc.ch.

DOI: $10.4187 /$ respcare.06694

\section{QUICK LOOK}

\section{Current knowledge}

The ability to stand up from a chair is an important component of maintaining independence among the elderly because this movement depends on stability and balance. The sit-to-stand (STS) test is a feasible tool for measuring peripheral muscle strength of the lower limbs. The STS test has been developed for different chronic diseases and elderly people. There is evidence of increasing use of the STS test in patients with COPD.

\section{What this paper contributes to our knowledge}

The 30-s STS test was a sensitive tool to assess the efficacy of pulmonary rehabilitation in subjects with stable COPD. A change of at least 2 repetitions represented the minimum clinically important difference of 30-s STS test after pulmonary rehabilitation. This minimum clinically important difference may be predicted by baseline ability in the 30-s STS and lung function tests in terms of overall lung capacity.

in the results of the 30-s STS test before and after PR. The minimum clinically important difference was retrospectively evaluated using an anchor-based method. Accordingly, on day 1 of the study, we performed a medical evaluation including medical history, physical examination, pulmonary function tests, and blood gas analysis. The next morning, subjects performed a 6MWT and, in the afternoon, a 30-s STS test. Before discharge, subjects repeated these functional assessments. Differences between initial and final values were calculated.

The study was approved by the institutional review board of the Malcantonese Hospital, 6980 Castelrotto, Switzerland. The procedures were performed from September 1, 2016, to August 31, 2017. No additional or external funding was used to support this study.

\section{Subjects}

We enrolled 100 subjects with COPD who attended an in-hospital PR program. The majority of subjects were sedentary and homebound. All subjects had a diagnosis of COPD according to Global Initiative for Chronic Obstructive Lung Disease criteria. Patients who had experience an exacerbation within the previous 4 weeks were excluded. Patients who did not complete the PR program due to COPD exacerbation or any unstable medical condition were also excluded. Contraindications for participation in the PR program included musculoskeletal disorders, malignant diseases, unstable cardiac condition, and lack of ad- 


\section{0-s Sit-to-Stand Test in Subjects With COPD}

herence to the program. All subjects had smoking history $\geq 10$ pack-years and received regular treatment with inhaled bronchodilators and inhaled steroids according to current guidelines for their disease stage. Each subject signed an informed consent form.

\section{Pulmonary Function Tests and Arterial Blood Gas Analysis}

$\mathrm{FVC}, \mathrm{FEV}_{1}$, total lung capacity (TLC), and residual volume (RV) were measured with a flow-sensing spirometer and a body plethysmograph connected to a computer for data analysis (Masterlab, Jaeger, Wurzburg, Germany). The transfer coefficient of the lung for carbon monoxide $\left(\mathrm{K}_{\mathrm{CO}}\right)$ was measured with the single-breath method using a mixture of carbon monoxide and methane (Sensor Medics, Yorba Linda, California). FVC, FEV 1 TLC, RV, and $\mathrm{K}_{\mathrm{CO}}$ were expressed as a percentage of predicted values, which were obtained from regression equations by Quanjer et al and Cotes et al. ${ }^{21,22} \mathrm{FEV}_{1} / \mathrm{FVC}$ and $\mathrm{RV} / \mathrm{TLC}$ ratios were taken as indices of airway obstruction and lung hyperinflation, respectively.

$\mathrm{P}_{\mathrm{aO}_{2}}$ and $\mathrm{P}_{\mathrm{aCO}_{2}}$ were measured immediately after sampling from a puncture of the radial artery with the $\mathrm{ABL}$ 90 Flex gas analyzer (Radiometer, Copenhagen, Denmark).

\section{Sit-to-Stand Test}

A straight-backed armless chair with a hard seat was stabilized by placing it against a wall. The height from floor to seat was $47 \mathrm{~cm}$. Seated participants were asked to come forward on the chair seat until the feet were flat on the floor and to fold their upper limbs across the chest. Participants were then instructed to stand up all the way and sit down once without using the upper limbs. Subjects started seated in the chair and, upon command, stood up and returned to sitting as many times as possible in $30 \mathrm{~s}$.

\section{Walking Capacity}

Walking capacity was evaluated by means of the distance covered during a 6MWT (6MWD) according to the American Thoracic Society statement. ${ }^{23}$ The 6MWT was performed by all subjects in a $30-\mathrm{m}$, level, indoor corridor in the hospital, under the supervision of a physiotherapist, according to American Thoracic Society guidelines. All subjects received the same instructions before the walk and were encouraged by the physiotherapist, who repeated set phrases every minute during the walk. A practice $6 \mathrm{MWT}$ was not performed. The 6MWD was recorded in meters. Subjects were allowed to stop and rest during the test but were instructed to resume walking as soon as they felt able to do so.

\section{Pulmonary Rehabilitation Program}

According to international recommendations, ${ }^{3}$ the PR program was completely tailored to suit the needs of the individual. The program consisted of 15 sessions over a 3 -week period. To be included in the study, subjects had to complete at least 12 supervised sessions. Lower-limb endurance training was the main component of the PR program. All subjects completed sessions of 30-40 min, using a treadmill or cycle-ergometer, depending on the clinically based choice of the physiotherapist and on the subject's preference. Exercise intensity was based on the initial 6MWT, and subjects started their training at $60-70 \%$ of the maximum heart rate achieved on the 6MWT. ${ }^{24}$ Exercises were then adjusted based on subject tolerance (at least weekly) with the aim of achieving a Borg dyspnea score of 3-5 (moderate to severe). To optimize training load, we provided supplemental oxygen to subjects with chronic respiratory failure and interval training for those who were compromised. Transcutaneous arterial oxygen saturation, blood pressure, and heart rate were monitored during every exercise session. Each session also included supervised upper-limb training; subjects used arm ergometer or performed calisthenic exercises holding a light weight. In relation to the subject's needs, the PR program could also include other components, such as airway-clearance techniques, pursed-lip breathing, and forced expiratory technique, as well as inspiratory muscle training using threshold-loading devices. Finally, each subject participated in educational activities on an individual basis at least 2 times regarding self-management, airway-clearance techniques, adherence to therapy, and nutritional support. The total daily duration of activities was $2-3 \mathrm{~h}$, and the entire program was conducted in the hospital.

\section{Statistical Analysis}

A Shapiro-Wilk test was used to analyze whether data were normally distributed. Data were described as median (first quartile, third quartile) for continuous variables with non-normal distribution, and as mean $\pm \mathrm{SD}$ were used for normally distributed data. Categorical variables were compared using the chi-square test or the Fisher exact test, and continuous variables were compared with the $t$ test or the nonparametric Mann-Whitney test.

Univariate and multivariate regression logistic models (stepwise) were performed to predict the probability of having a $\Delta 30$-s STS $\geq 2$ repetitions as the dependent variable. The variables included in the univariate analysis were age, gender (male/female), body mass index, modified Medical Research Council dyspnea scale score $(\geq 2), \mathrm{FEV}_{1}(\leq 50 \%$ predicted), the RV/TLC ratio $(<58 \%)$, baseline dyspnea index ( $>6$ points), $\mathrm{P}_{\mathrm{aO}_{2}}(<71 \mathrm{~mm} \mathrm{Hg})$, $\mathrm{P}_{\mathrm{aCO}_{2}}(<39 \mathrm{~mm} \mathrm{Hg})$, diffusing capacity for carbon mon- 
Table 1. General Characteristics of Study Cohort

\begin{tabular}{|c|c|}
\hline Age, y & $71.4 \pm 7.2$ \\
\hline Male, $\%$ & 72 \\
\hline Body mass index, $\mathrm{kg} / \mathrm{m}^{2}$ & $24.7 \pm 4.9$ \\
\hline Pack/year & $50(40-61.2)$ \\
\hline mMRC dyspnea score & $2(1-3)$ \\
\hline Baseline dyspnea index, total score & $6(3-7)$ \\
\hline $\mathrm{FEV}_{1}, \%$ pred. & $43.1(36-54.6)$ \\
\hline $\mathrm{FEV}_{1} / \mathrm{FVC}, \%$ & $45.6 \pm 12.0$ \\
\hline RV/TLC, \% & $59.1 \pm 10.0$ \\
\hline $\mathrm{D}_{\mathrm{LCO}}, \%$ predicted & $53.0 \pm 13.2$ \\
\hline $\mathrm{P}_{\mathrm{aO}_{2}}, \mathrm{~mm} \mathrm{Hg}$ & $71(64-76.9)$ \\
\hline $\mathrm{P}_{\mathrm{aCO}_{2}}, \mathrm{~mm} \mathrm{Hg}$ & $39(35.8-42.9)$ \\
\hline 6MWD baseline, $\mathrm{m}$ & $410(338.7-473)$ \\
\hline 30-s STS baseline, repetitions & $12(9.25-13)$ \\
\hline \multicolumn{2}{|c|}{$\begin{array}{l}N=96 \text { subjects. Data are shown as mean } \pm \text { SD or median (interquartile range) unless } \\
\text { otherwise stated. } \\
\text { mMRC = modified Medical Research Council scale } \\
\text { RV/TLC }=\text { residual volume/total lung capacity } \\
\mathrm{D}_{\mathrm{LCO}}=\text { diffusing capacity for carbon monoxide } \\
6 \mathrm{MWD}=6 \text {-min walk distance } \\
\text { 30-s STS }=30 \text {-s sit-to-stand test }\end{array}$} \\
\hline
\end{tabular}

oxide $\left(\mathrm{D}_{\mathrm{LCO}}<53 \%\right.$ predicted $)$, baseline $6 \mathrm{MWD}(<350 \mathrm{~m})$, and baseline 30-s STS test ( $<12$ repetitions). For RV/TLC, baseline dyspnea index, $\mathrm{P}_{\mathrm{aO}_{2}}, \mathrm{P}_{\mathrm{aCO}_{2}}, \mathrm{D}_{\mathrm{LCO}}$, and baseline $30-\mathrm{s}$ $\mathrm{STS}$, median values were used to define categories according to better or worse characteristics.

To evaluate the minimum clinically important difference, $\Delta$ 30-s STS after PR was anchored against changes in other outcome measures of PR efficacy. ${ }^{25}$ The receiver operating characteristic (ROC) curve method ${ }^{26}$ was used to plot the true positive rate (sensitivity) as a function of the false positive rate (1-specificity) for different cut-off points of the 30-s STS repetitions. The minimum clinically important difference for 6MWD ( $\geq 30 \mathrm{~m}$ ) and transitional dyspnea index ( $\geq 1$ ) were considered as the threshold values. ${ }^{27,28}$ The 30-s STS cut-off point, which maximized sensitivity and specificity, was chosen as the minimum clinically important difference.

Variables that showed a significant result $(P<.10)$ were included in the corresponding multivariate regression stepwise model. Variables presenting high collinearity (Pearson $r> \pm 0.30$ ) were excluded from the multivariate analysis. Odds ratios and 95\% CI were then calculated. $P<.05$ was considered significant for all analyses. The analyses were performed with IBM SPSS Statistics 25.0 (Armonk, New York).

\section{Results}

96 subjects with moderate-to-severe COPD completed the procedures and were included. Characteristic of the subjects at baseline are reported in Table 1.
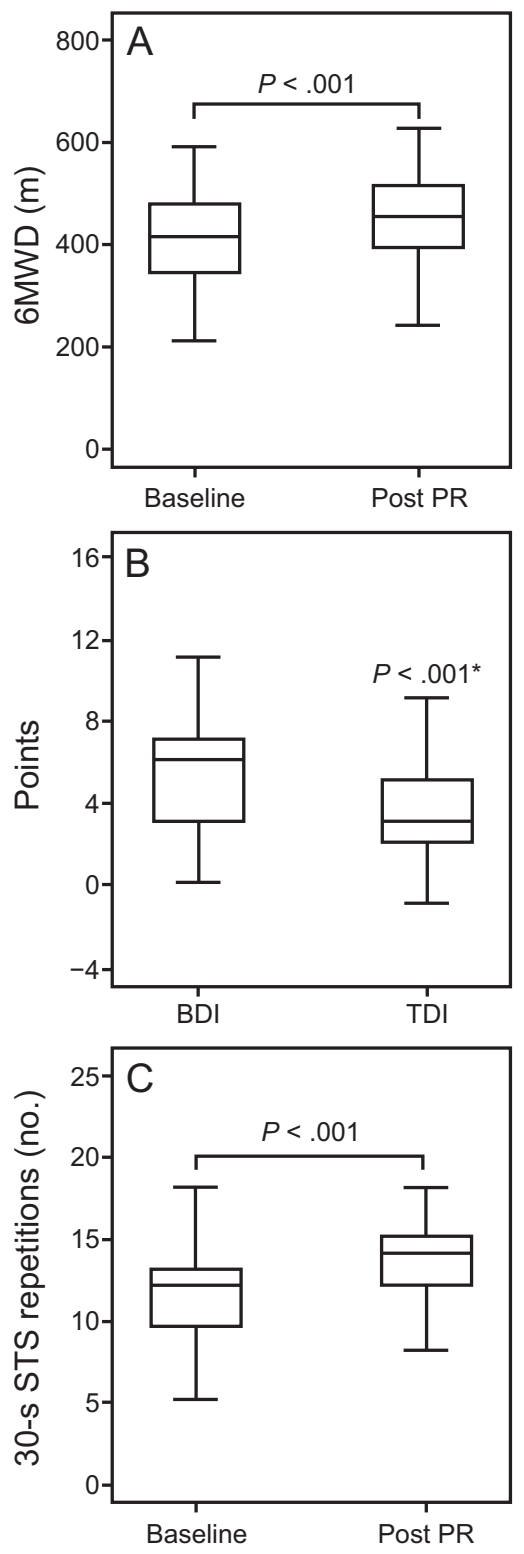

Fig. 1. Change in A: 6MWD $(\Delta$ mean $+42 \mathrm{~m})$; B: BDI/TDI (mean +3.35 points); C: 30 -s STS $(\Delta$ mean +2.07 repetitions) before and after pulmonary rehabilitation. ${ }^{*} P$ value calculated versus value 0 (ie, no change from BDI). $6 \mathrm{MWD}=6$-min walk distance, $\mathrm{PR}=$ pulmonary rehabilitation, $\mathrm{BDI}=$ baseline dyspnea index, $\mathrm{TDI}=$ transitional dyspnea index, 30-s STS $=30$-s sit-to-stand test.

The main parameters linked with 30-s STS repetitions at baseline were as follows: 6MWD $(r=0.65, P<.001)$, FVC $(r=0.46, P<.001), \mathrm{P}_{\mathrm{aCO}_{2}}(r=-0.42, P<.001)$, $\mathrm{FEV}_{1}(r=0.39, P<.001)$, and age $(r=-0.31, P=.002)$.

All subjects showed a significant improvement in 30-s STS test results, 6MWD, and transitional dyspnea index after PR (Fig. 1). Notably, a mean difference of 2 repetitions $(P<.001)$ was observed for the 30 -s STS tests. The change in 30-s STS test results was positively related to the change in 6MWD $(r=0.62, P<.001)$, transitional 

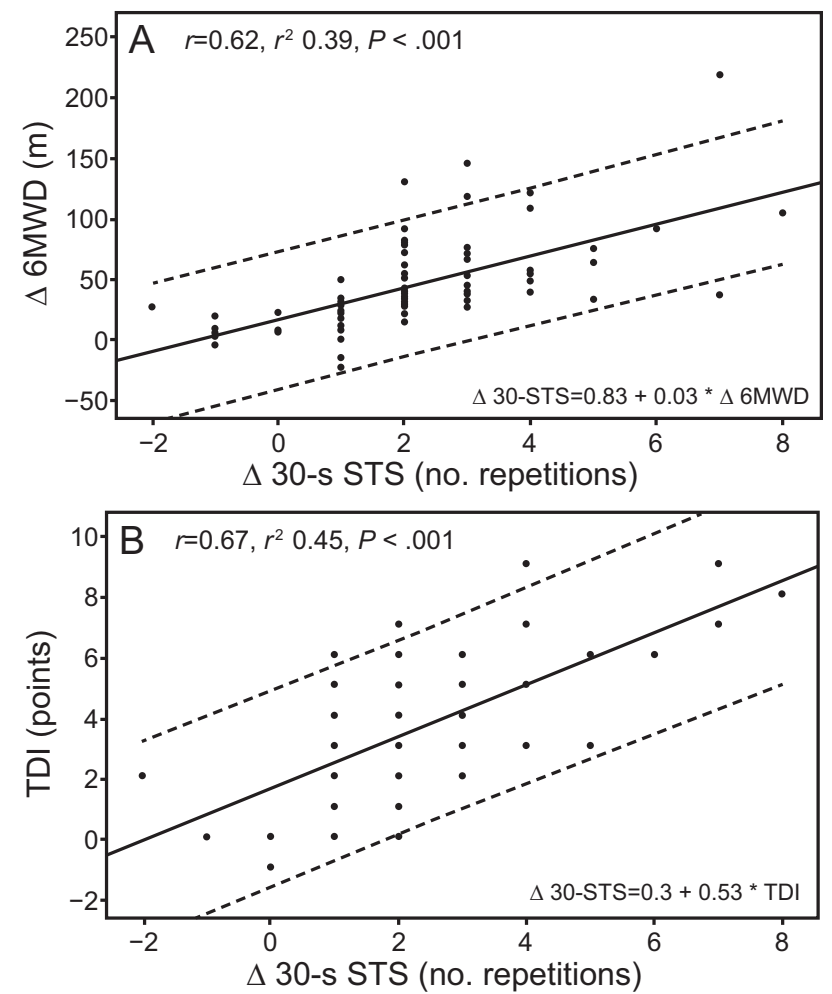

Fig. 2. A: Correlation between change $(\Delta)$ in 6MWD and 30-STS test before and after pulmonary rehabilitation. B: Correlation between change before and after pulmonary rehabilitation $(\Delta)$ in TDI and 30-s STS test. 6MWD $=6$-min walk distance, TDI $=$ transitional dyspnea index, 30 -s STS $=30$-s sit-to-stand.

dyspnea index $(r=0.67, P<.001)$, and baseline RV $(r=0.27, P=.007)$ (Fig. 2). The ROC curves to identify the best change in 30-s STS test results to distinguish between those achieving the minimum clinically important difference for $\triangle 6 \mathrm{MWD}$ and transitional dyspnea index are shown in Figure 3. According to the ROC curve method, the plots of the true positive rate as a function of the false positive rate for different cut-off points of 30-s STS repetitions with respect to $\Delta 6 \mathrm{MWD} \geq 30 \mathrm{~m}$ and transitional dyspnea index $\geq 1$, as threshold values, showed 0.907 and 0.885 area under curve values, respectively. The $\Delta 30$-s STS cut-off point, which maximized sensitivity and specificity, was $\geq 2$ (0.929 sensitivity and 0.800 specificity, and 0.734 sensitivity and 0.882 specificity, respectively).

According to the proposed minimum clinically important difference for $\Delta 30$-s STS, 60 of 96 subjects (62\%) improved after PR, showing a $\Delta 30$-s STS $\geq 2$. Compared with unchanged subjects in 30-s STS, the improved subjects showed significantly worse respiratory function (airflow obstruction and diffuse lung capacity), symptoms (dyspnea), and peripheral muscle strength of the lower limbs (30-s STS) at baseline (Table 2). The distribution of subjects with $\Delta 30$-s STS $\geq 2$ or $<2$, according to the different cut-off of $\Delta 6 \mathrm{MWD}$ (ie, $\leq 30 \mathrm{~m}$ or $>30 \mathrm{~m}$ ) and transitional dyspnea index ( $\leq 1$ point or $>1$ point), are shown in Figure 4.

Table 3 shows the results of the univariate and multivariate analyses, taking a $\Delta 30$-s STS $\geq 2$ repetitions after $\mathrm{PR}$ as the dependent variable, and taking the modified Medical Research Council dyspnea scale score $(\geq 2), F_{1}$ ( $\leq 50 \%$ predicted), 30 -s STS baseline ( $<12$ repetitions), $6 \mathrm{MWD}$ baseline $(<350 \mathrm{~m})$, and $\mathrm{D}_{\mathrm{LCO}}(<53 \%$ predicted $)$ as independent variables. Univariate analyses shows that the change in 30-s STS was significantly associated with all of the independent variables, whereas only 30-s STS and $\mathrm{D}_{\mathrm{LCO}}$ at baseline were associated with $\Delta 30$-s STS in multivariate analyses.

In a multivariate logistic regression model, $<12$ repetitions at baseline 30-s STS (odds ratio 2.63, 95\% CI 1.09$6.35, P=.031)$, and $\mathrm{D}_{\mathrm{LCO}}(<53 \%$ predicted) (odds ratio $2.49,95 \%$ CI $1.04-5.98, P=.041)$ predict the probability of having $\Delta 30$-s STS $\geq 2$ repetitions.

\section{Discussion}

In this retrospective study, we investigated the role of a 3 -week PR program in improving peripheral muscle strength of the lower limbs as evaluated with the 30-s STS in 96 stable subjects with COPD. As expected, a significant improvement in 30-s STS repetitions in all subjects was found after PR. In addition, we determined a minimum clinically important difference for 30-s STS of at least 2 repetitions, which is able to discriminate between improved and unchanged subjects with COPD, suggesting the potential utility of this parameter in clinical settings. Furthermore, we found that improved subjects, as assessed with the 30-s STS, were characterized by worse respiratory function at baseline and higher changes in 6MWD and transitional dyspnea index after PR.

The STS test was first introduced by Csuka and McCarty ${ }^{29}$ as a measure of lower-limb strength, and this test remains an important marker of an independent lifestyle. The original version of the STS test required a subject to perform 10 STS repetitions from a standard chair, and the time required to perform 10 repetitions was recorded. Over the years, different versions of the test have been used in different populations. Jones et $\mathrm{al}^{30}$ introduced a version of the STS test conducted over $30 \mathrm{~s}$, which was designed to measure lower limb strength in older adults. Unlike STS tests that involve a 1-min period or 5 repetitions, the 30-s STS test in patients with COPD has not been extensively investigated. In particular, the study by Butcher et $\mathrm{al}^{31}$ reported the validity of this test as a surrogate to evaluate muscle strength by presenting good correlations between the 30-s STS test and quadriceps strength. That study aimed to examine links between muscular performance using different modalities of contraction and functional performance (ie, concentric, eccentric, and isometric contractions). ${ }^{31} \mathrm{In}$ 


\section{0-s Sit-to-Stand Test in Subjects With COPD}
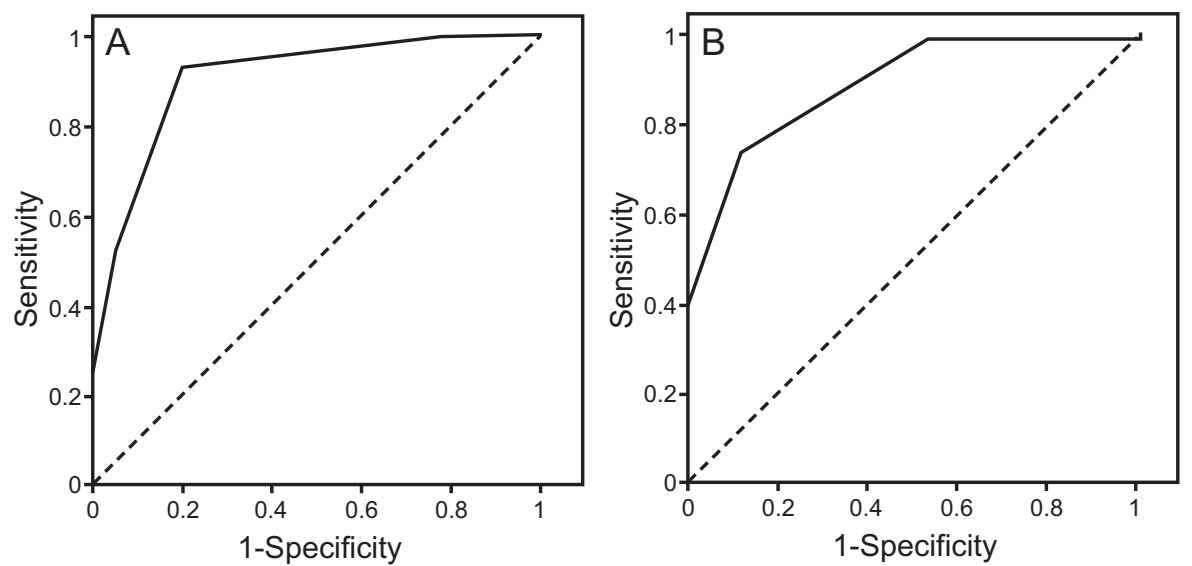

Fig. 3. Receiver operating characteristic curves performed with state variables $\Delta 6 \mathrm{MWD}(>30 \mathrm{~m})$ and transitional dyspnea index ( $>1$ point) to anchor the value of $\Delta 30$-s STS. A: Area under the curve for $\Delta 6 \mathrm{MWD}=0.907$, standard error $0.031,95 \% \mathrm{Cl} 0.845-0.968, P<.001$, $\Delta 30$-s STS $=1.5$, sensitivity 0.929 , specificity 0.800 . B: Area under the curve for transitional dyspnea index $=0.885$, standard error 0.041 , $95 \% \mathrm{Cl} 0.806-0.965, P<.001, \Delta 30$-s STS $=1.5$, sensitivity 0.734 , specificity 0.882 .

Table 2. General Characteristics of Study Cohort According to the Cut-Off of 2 Repetitions in the $\Delta 30$-s STS Test

\begin{tabular}{|c|c|c|c|}
\hline Variables & $\Delta 30$-s STS $<2$ Repetitions & $\Delta 30$-s STS $\geq 2$ Repetitions & $P$ \\
\hline Age, y & $71.4 \pm 7.5$ & $71.5 \pm 7.0$ & .80 \\
\hline Male, $\%$ & 76 & 69 & .54 \\
\hline Body mass index, $\mathrm{kg} / \mathrm{m}^{2}$ & $25.8 \pm 5.4$ & $24.0 \pm 4.6$ & .10 \\
\hline mMRC dyspnea score & $2(1-2)$ & $2(2-3)$ & $<.001$ \\
\hline $\mathrm{FEV}_{1}, \%$ pred. & $49.8(39.5-59.7)$ & $40(34.8-51.5)$ & .02 \\
\hline $\mathrm{FEV}_{1} / \mathrm{FVC}, \%$ & $47.0 \pm 11.9$ & $44.8 \pm 12.1$ & .38 \\
\hline RV/TLC, \% & $57.2 \pm 10.2$ & $60.2 \pm 9.8$ & .15 \\
\hline $\mathrm{D}_{\mathrm{LCO}}, \%$ pred. & $56.5 \pm 12.0$ & $50.9 \pm 13.5$ & .047 \\
\hline $\mathrm{P}_{\mathrm{aO}_{2}}, \mathrm{~mm} \mathrm{Hg}$ & $71.2(65.1-77.5)$ & $70.4(63-76)$ & .24 \\
\hline $\mathrm{P}_{\mathrm{aCO}_{2}}, \mathrm{~mm} \mathrm{Hg}$ & $39(35.2-42.3)$ & $39(37-44)$ & .77 \\
\hline 6MWD baseline, $\mathrm{m}$ & $426.5(392-494.5)$ & $397(320.5-457.5)$ & .03 \\
\hline Baseline dyspnea index total score & $6.5(3-7)$ & $5(3.25-7)$ & .27 \\
\hline $\mathrm{FEV}_{1}, \%$ pred. & $13(11-14)$ & $11(9-13)$ & .02 \\
\hline$\Delta 6 \mathrm{MWD}, \mathrm{m}$ & $17(6.25-26)$ & $48(35.2-70.7)$ & $<.001$ \\
\hline Transitional dyspnea index score & $2(0-3)$ & $4(3-5)$ & $<.001$ \\
\hline $\mathrm{FEV}_{1}, \%$ pred. & $1(0.25-1)$ & $3(2-3)$ & $<.001$ \\
\hline
\end{tabular}

$\overline{n=36 \text { subjects with } \Delta}$ 30-s STS $<2$ repetitions; $n=60$ subjects with $\Delta 30$-s STS $\geq 2$ repetitions. Data are shown as mean \pm SD or median (interquartile range) unless otherwise stated. $\mathrm{mMRC}=$ modified Medical Research Council scale

$\mathrm{RV} / \mathrm{TLC}=$ residual volume/total lung capacity

$\mathrm{D}_{\mathrm{LCO}}=$ diffusing capacity for carbon monoxide

$6 \mathrm{MWD}=6$-min walk test distance

a previous study, we found significant correlations between the 30-s STS test (ie, number of repetitions) and the 1-repetition maximum strength test (ie, the greatest amount of weight lifted in a single repetition), which is considered the accepted standard for muscle strength assessment in the clinical setting. ${ }^{18} \mathrm{We}$ also reported a good correlation between the 30-s STS and 6MWT, which suggests that the 30 -s STS test may also be an alternative to the 6MWT to measure functional exercise performance in subjects with COPD. ${ }^{18}$ Furthermore, we reported a significant improvement in 30-s STS test performance after PR; this is clin- ically relevant because strength training has a greater potential to improve muscle mass and strength with lower dyspnea grade than endurance training. ${ }^{18}$

In this study, we confirmed the responsiveness of the 30-s STS test to PR, with a mean difference of 2 repetitions, and we provided the first indication of a minimum clinically important difference in performing the 30-s STS test after PR in subjects with COPD. We reported a minimum clinically important difference that was comparable with the results of Vaidya et $\mathrm{al}^{19}$ and Crook et al, ${ }^{20}$ which indicated a minimum clinically important difference for 

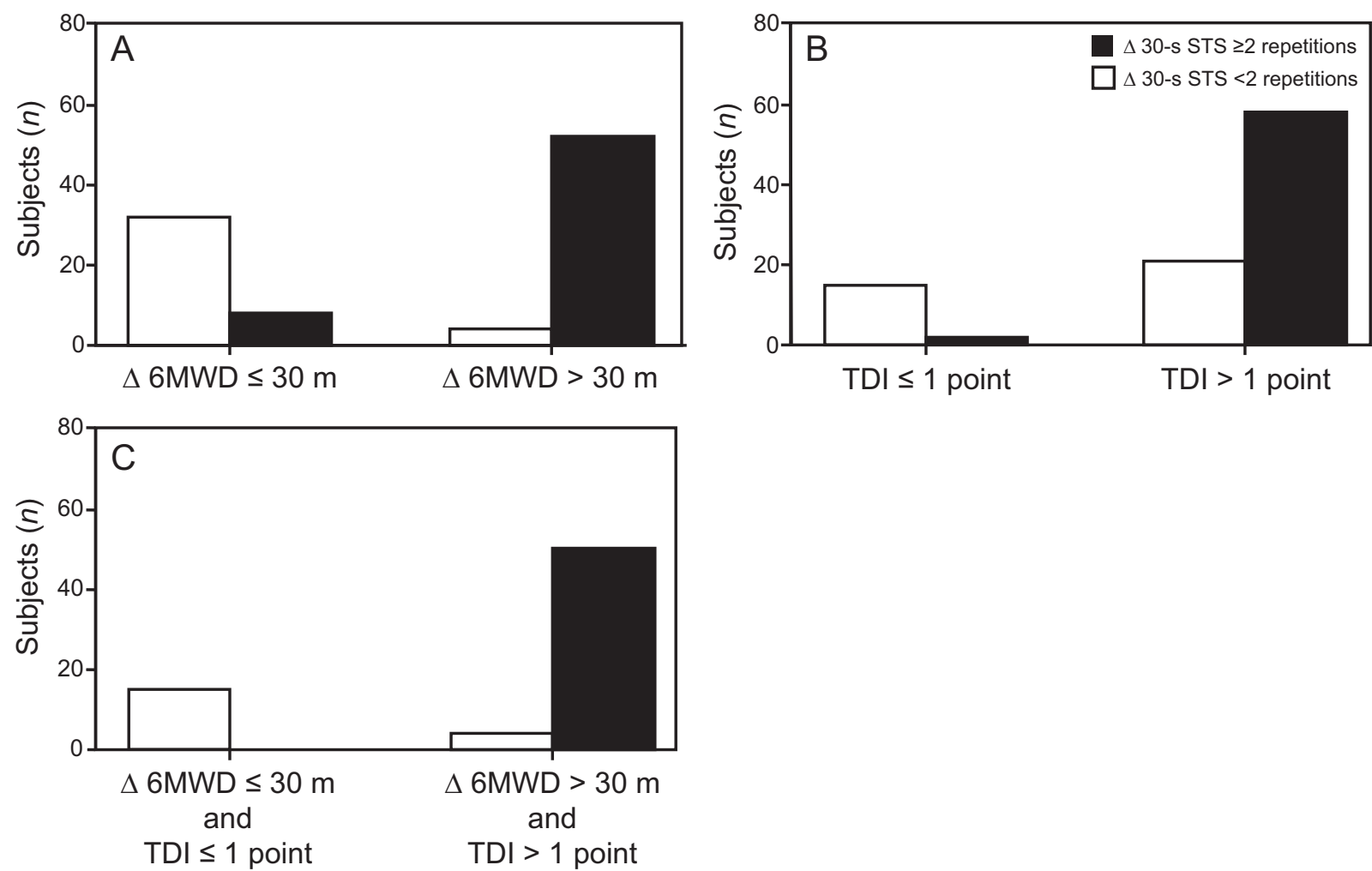

Fig. 4. Distribution of subjects with $\Delta 30$-s STS ( $\geq 2$ repetitions or $<2$ repetitions) according different cut-offs of $\Delta 6 \mathrm{MWD}$ ( $\leq 30 \mathrm{~m}$ or $>30 \mathrm{~m}$ ) and TDI ( $\leq 1$ point or $>1$ point). $6 \mathrm{MWD}=6$-min walk distance, $\mathrm{PR}=$ pulmonary rehabilitation, TDI $=$ transitional dyspnea index, 30 -s STS $=30$-s sit-to-stand test.

Table 3. Univariate and Multivariate Analysis Predicting the Probability of a $\Delta 30$-s STS $\geq 2$ Repetitions

\begin{tabular}{|c|c|c|c|c|}
\hline \multirow{2}{*}{ Variables } & \multicolumn{2}{|c|}{ Univariate } & \multicolumn{2}{|c|}{ Multivariate } \\
\hline & Odds Ratio $(95 \% \mathrm{CI})$ & $P$ & Odds Ratio $(95 \% \mathrm{CI})$ & $P$ \\
\hline mMRC dyspnea score $(\geq 2)$ & $3.20(1.28-7.96)$ & .01 & & \\
\hline $\mathrm{FEV}_{1}(\leq 50 \%$ pred. $)$ & $2.67(1.12-6.38)$ & .03 & & \\
\hline 30-s STS baseline $(<12$ repetitions)* & $2.61(1.10-6.18)$ & .03 & $2.63(1.09-6.35)$ & .031 \\
\hline $6 \mathrm{MWD}$ baseline $(<350 \mathrm{~m})$ & $3.33(1.13-9.86)$ & .03 & & \\
\hline $\mathrm{D}_{\mathrm{LCO}}(<53 \% \text { pred. })^{*}$ & $2.48(1.05-5.80)$ & .037 & $2.49(1.04-5.98)$ & .041 \\
\hline $\begin{array}{l}\text { Hosmer and Lemeshow goodness-of-fit tests: } P=.9 \\
\text { * Defined according to the median value. } \\
\text { mMRC }=\text { modified Medical Research Council scale } \\
\text { 30-s STS = 30-s sit-to-stand test } \\
\text { 6MWD = 6-min walk test distance } \\
\mathrm{D}_{\mathrm{LCO}}=\text { diffusing capacity for carbon monoxide }\end{array}$ & model. & & & \\
\hline
\end{tabular}

1-min STS; this was interesting considering the difference in the test time.

In addition, we confirmed a significant relationship between lung function and the 30-s STS test results at baseline. Subjects with better preserved pulmonary function had higher lower-limb strength performance. Previous studies showed discordant results. No correlation between pulmonary function, expressed as $\mathrm{FEV}_{1}$, and lower-limb strength performance, as evaluated with a 1-min STS test or a 5-repetition STS test, was reported. ${ }^{10,13}$ On the other hand, Bernard et $\mathrm{al}^{32}$ found that quadriceps strength, measured during dynamic contractions against a hydraulic resistance, correlated positively with $\mathrm{FEV}_{1}$ expressed as percentage of predicted. Moreover, Seymour et $\mathrm{al}^{33}$ reported that the highest prevalence of quadriceps weakness, evaluated as isometric quadriceps maximum voluntary contraction strength, was found in subjects with COPD with the most severe air-flow obstruction. 


\section{0-s Sit-to-Stand Test in Subjects With COPD}

When we divided our subjects into 2 groups (ie, improved subjects and unchanged subjects according to the minimum clinically important difference for the 30-s STS test), we noted that those who improved had significantly worse lung function (ie, air-flow obstruction, hyperinflation, diffuse lung capacity) and baseline ability in the 30-s STS test compared to those who were unchanged. Moreover, the improved group obtained a greater change in 6MWD and transitional dyspnea index after PR than the unimproved group. It is possible that subjects with poor baseline lung function are at risk to enter a downward spiral of dyspnea, sedentariness, demotivation, and, finally, deconditioning. ${ }^{34}$ It is of note that our results showed that these subjects may have a larger improvement after PR compared to subjects with more preserved lung function and exercise capacity.

Regarding the use of various modalities of the STS test, the different procedures do not necessarily reflect the same physical aptitudes, and they are not completely interchangeable. It is reasonable that the shorter versions (ie, 5-repetition STS test, 30-s STS test) are more relevant as an estimate of physical activities that are performed over a short time period, such as strength and speed. In this way, because anaerobic exercise performance is predominant, they provide a measure of deficit in muscle strength and, more precisely, quadriceps weakness. ${ }^{13,31,35,36}$ In longer versions of STS tests (eg, 1 min or longer), aerobic processes are also involved, making them more suitable to evaluate exercise capacity and tolerance, with a physiological response comparable to that of the 6MWT.20,36 Recently, Morita et $\mathrm{al}^{37}$ compared the 5-repetition, the 30-s STS, and the 1-min STS test protocols and evaluated their correlations with clinical and functional outcomes in a small sample of subjects with COPD. Although all 3 tests were able to identify individuals with low exercise capacity or preserved exercise capacity, the study reported that the 1-min STS test correlated better with clinical outcomes in subjects with COPD, even if it generated higher hemodynamic demands. ${ }^{37}$ In line with these findings, we reported in a previous study that the 1-min STS test induced a higher fatigue perception and greater oxygen desaturation in subjects with COPD compared to the 1-repetition maximum strength test. ${ }^{18}$

Despite reporting original findings with potential clinical importance, this study has some limitations. We acknowledge that the STS test does not necessarily evaluate lower-limb strength performance, but it may be an indicator of balance, postural control, mobility, or even cognitive and psychological status as observed in older people. ${ }^{9}$ Moreover, the retrospective design might limit the validity of the results obtained. Thus, further prospective studies are required.

\section{Conclusion}

We report that in stable subjects with moderate-to-severe COPD, the 30-s STS test was a sensitive tool to assess PR efficacy. Furthermore, a change of at least 2 repetitions in the 30-s STS test results represented the minimum clinically important difference, which may be predicted by baseline ability in the 30-s STS and lung function tests in terms of overall lung capacity.

\section{REFERENCES}

1. Debigare R, Cote C, Maltais F. Peripheral muscle wasting in chronic obstructive pulmonary disease: clinical relevance and mechanisms. Am J Respir Crit Care Med 2001;164(9):1712-1717.

2. American Thoracic Society/European Respitaratory Society. Skeletal muscle dysfunction in chronic obstructive pulmonary disease. Am J Respir Crit Care Med 1999;159(4 Pt 2):1-40.

3. Spruit MA, Singh SJ, Garvey C, ZuWallack R, Nici L, Rochester C, et al. An official American Thoracic Society/European Respiratory Society statement: key concepts and advances in pulmonary rehabilitation. Am J Respir Crit Care Med 2013;188:13-64.

4. Spruit MA, Gosselink R, Troosters T, De Paepe K, Decramer M. Resistance versus endurance training in patients with COPD and peripheral muscle weakness. Eur Respir J 2002;(6)19:1072-1078.

5. Ortega F, Toral J, Cejudo P, Villagomez R, Sánchez H, Castillo J, Montemayor T. Comparison of effects of strength and endurance training in patients with chronic obstructive pulmonary disease. Am J Respir Crit Care Med 2002;(5)166:669-674.

6. Simpson K, Killian K, McCartney N, Stubbing DG, Jones NL. Randomised controlled trial of weightlifting exercise in patients with chronic airflow limitation. Thorax 1992(2)47:70-75.

7. Troosters T, Probst VS, Crul T, Pitta F, Gayan-Ramirez G, Decramer M, Gosselink R. Resistance training prevents deterioration in quadriceps muscle function during acute exacerbations of COPD. Am J Respir Crit Care Med 2010;181(10):1072-1077.

8. Bohannon RW. Sit-to-stand test for measuring performance of lower extremity muscles. Percept Mot Skills 1995;80(1):163-166.

9. Lord SR, Murray SM, Chapman K, Munro B, Tiedemann A. Sit-tostand performance depends on sensation, speed, balance, and psychological status in addition to strength in older people. J Gerontol A Biol Sci Med Sci 2002;58(8):M539-M543.

10. Ozalevli S, Ozden A, Itil O, Akkoclu A. Comparison of the sit-tostand test with 6 min walk test in patients with chronic obstructive pulmonary disease. Respir Med 2007;101(2):286-293.

11. Puhan MA, Siebeling L, Zoller M, Muggensturm P, ter Riet G. Simple functional performance tests and mortality in COPD. Eur Respir J 2013;42(4):956-963.

12. Reychler G, Boucard E, Peran L, Pichon R, Le Ber-Moy C, Ouksel $\mathrm{H}$, et al. One-minute sit-to-stand test is an alternative to 6MWT to measure functional exercise performance in COPD patients. Clin Respir J 2018;12(3):1247-1256.

13. Jones SE, Kon SS, Canavan JL, Patel MS, Clark AL, Nolan CM, et al. The five-repetition sit-to-stand test as a functional outcome measure in COPD. Thorax 2013;68(11):1015-1020.

14. Ritchie C, Trost SG, Brown W, Armit C. Reliability and validity of physical fitness field tests for adults aged 55 to 70 years. J Sci Med Sports 2005;8(1):61-70.

15. Bohannon RW. Reference values for the five-repetition sit-to-stand test: a descriptive meta-analysis of data from elders. Percept Mot Skills 2006;103(1):215-222. 


\section{0-s Sit-to-Stand Test in Subjects With COPD}

16. Strassmann A, Steurer-Stey C, Dalla Lana K, Zoller M, Turk AJ, Suter P, Puhan MA. Population-based reference values for the 1-min sit-to-stand test. Int J Public Health 2013;58(6):949-953.

17. Tveter AT, Dagfinrud H, Moseng T, Holm I. Health-related physical fitness measures: reference values and reference equations for use in clinical practice. Arch Phys Med Rehabil 2014;95(7):1366-1373.

18. Zanini A, Aiello M, Cherubino F, Zampogna E, Azzola A, Chetta A, Spanevello A. The one repetition maximum test and the sit-to-stand test in the assessment of a specific pulmonary rehabilitation program on peripheral muscle strength in COPD patients. Int J Chron Obstruct Pulmon Dis 2015;10:2423-2430.

19. Vaidya T, de Bisschop C, Beaumont M, Ouksel H, Jean V, Dessables F, Chambellan A. Is the 1-minute sit-to-stand test a good tool for the evaluation of the impact of pulmonary rehabilitation? Determination of the minimal important difference in COPD. Int J Chron Obstruct Pulmon Dis 2016;11:2609-2616.

20. Crook S, Büsching G, Schultz K, Lehbert N, Jelusic D, Keusch S, et al. A multicentre validation of the 1-min sit-to-stand test in patients with COPD. Eur Respir J 2017;49(3):1-11.

21. Quanjer PH, Tammeling GJ, Cotes JE, Pedersen OF, Peslin R, Yernault JC. Lung volumes and forced ventilatory flows. Report Working Party Standardization of Lung Function Tests, European Community for Steel and Coal. Official Statement of the European Respiratory Society. Eur Respir J Suppl 1993;16:5-40.

22. Cotes JE, Chinn DJ, Quanjer PH, Roca J, Yernault JC. Standardization of the measurement of transfer factor (diffusing capacity). Report Working Party Standardization of Lung Function Tests, European Community for Steel and Coal Official Statement of the European Respiratory Society. Eur Respir J Suppl 1993;16:41-52.

23. ATS Committee on Proficiency Standards for Clinical Pulmonary Function Laboratories. ATS statement: guidelines for the six-minute walk test. Am J Respir Crit Care Med 2002;166(1):111-117.

24. Zainuldin MR, Knoke D, Mackey MG, Luxton N, Alison JA. Prescribing cycle training intensity from the six-minute walk test for patients with COPD. BMC Pulm Med 2007;7:9.

25. Make B. How can we assess outcomes of clinical trials: the MCID approach. COPD 2007;4(3):191-194.
26. Zweig MH, Campbell G. Receiver-operating characteristic (ROC) plots: a fundamental evaluation tool in clinical medicine. Clin Chem 1993;39(4):561-577.

27. Polkey MI, Spruit MA, Edwards LD, Watkins ML, Pinto-Plata V, Vestbo J, et al. Six-minute-walk test in chronic obstructive pulmonary diseases: minimal clinically important difference for death or hospitalization. Am J Respir Crit Care Med 2013;187(4):382-386.

28. Witek TJ, Mahler DA. Minimal important difference of the transitional dyspnea index in a multinational clinical trial. Eur Respir $\mathbf{J}$ 2003;21(2):267-272.

29. Csuka M, McCarty DJ. Simple method for measurement of lower extremity muscle strength. Am J Med 1985;78(1):77-81.

30. Jones CJ, Rikli RE, Beam WC. A 30-s chair-stand test as a measure of lower body strength in community-residing older adults. Res Q Exerc Sport 1999;70(2):113-119.

31. Butcher CJ, Pikaluk PJ, Chura RI, Walkner MJ, Farthing JP, Marciniuk DD. Associations between isokinetic muscle strength, highlevel functional performance, and physiological parameters in patients with chronic obstructive pulmonary disease. Int $\mathrm{J}$ Chron Obstruct Pulmon Dis 2012;7:537-542.

32. Bernard S, LeBlanc P, Whittom F, Carrier G, Jobin J, Belleau R, Maltais F. Peripheral muscle weakness in patients with chronic obstructive pulmonary disease. Am J Respir Crit Care Med 1998;158(2): 629-634.

33. Seymour JM, Spruit MA, Hopkinson NS, Natanek SA, Man WD-C, Jackson A, et al. The prevalence of quadriceps weakness in COPD and the relationship with disease severity. Eur Respir J 2010;36(1):81-88.

34. MacIntyre NR. Mechanisms of functional loss in patients with chronic lung disease. Respir Care 2008;53(9):1177-1184.

35. Janssens L, Brumagne S, McConnell AK, Claeys K, Pijnenburg M, Goossens N, Burtin C. Impaired postural control reduces sit-to-standto-sit performance in individuals with chronic obstructive pulmonary disease. PLoS One 2014;9(2):e88247.

36. Vaidya T, Chambellan A, de Bisschop C. Sit-to-stand tests for COPD: a literature review. Respir Med 2017;128:70-77.

37. Morita AA, Bisca GW, Machado FVC, Hernandes NA, Pitta F, Probst VS. Best protocol for the sit-to-stand test in subjects with COPD. Respir Care 2018;63(8):1040-1049. 